\title{
Aleloquímico Produzido pela Gramínea Forrageira Brachiaria humidicola ${ }^{1}$
}

\author{
Allelochemical Produced by the Forage Grass Brachiaria humidicola
}

SOUZA FILHO, A.P.S. ${ }^{2}$, PEREIRA, A.A.G. ${ }^{3}$ e BAYMA, J.C. ${ }^{4}$

\begin{abstract}
RESUMO - Os métodos usuais de controle de plantas daninhas não atendem mais as atuais e futuras exigências da sociedade em relação à preservação dos recursos naturais e da qualidade de vida. Uma alternativa para essa questão seriam os metabólitos secundários produzidos pelas plantas, que apresentam pouco risco para o ambiente e para os interesses da sociedade. Os objetivos deste trabalho foram isolar, identificar e caracterizar a atividade alelopática de substâncias químicas produzidas pela gramínea forrageira Brachiaria humidicola. Analisaram-se os efeitos alelopáticos dos extratos, frações e substâncias isoladas sobre a germinação e o desenvolvimento da radícula das invasoras malícia, fedegoso e mata-pasto, em bioensaios monitorados em periodos de 10 dias, em condições de $25{ }^{\circ} \mathrm{C}$ e fotoperíodo de 12 horas, para a germinação, e 24 horas, para o desenvolvimento da radícula. A partir do extrato hidrometanólico, foi isolado e identificado o ácido $p$-cumárico. Os efeitos alelopáticos estiveram positivamente relacionados à concentração do ácido, à espécie de planta daninha e à característica da espécie analisada. Comparativamente, fedegoso e malícia se mostraram mais sensiveis aos efeitos alelopáticos. A germinação e o desenvolvimento da radícula do mata-pasto não foram afetados pelo ácido $p$-cumárico nas concentrações de 1,0 a $8,0 \mathrm{mg} \mathrm{L}^{-1}$. $\mathrm{O}$ alongamento da radícula se mostrou mais sensível aos efeitos alelopáticos do ácido p-cumárico do que a germinação das sementes.
\end{abstract}

Palavras-chave: alelopatia, inibição, planta daninha, ácido $p$-cumárico.

\begin{abstract}
The traditional methods of weed control in cultivated pasture do not meet society's present and future needs of protecting natural resources and life quality. An alternative to this problem could be the use of secondary metabolites produced by plants. These products present few risks to the environment and meet society interests. Therefore, this research was carried out to isolate, identify and characterize the allelopathic activity of chemical compounds produced by the forage grass Brachiaria humidicola. The allelopathic effects of the extracts, fractions and compound were tested on seed germination and root elongation of the weeds Mimosa pudica, Senna obtusifolia and Senna occidentalis. Germination bioassays were developed under $25{ }^{\circ} \mathrm{C}$ and a photoperiod of 12 hours. For root elongation, the bioassay conditions were $25^{\circ} \mathrm{C}$ and photoperiod of 24 hours. Hydromethanolic extract was used as a source for isolating and identifying $\mathrm{p}$-coumaric acid. The allelopathic effects were positively related to $\mathrm{p}$-coumaric acid concentration, weed species and the evaluated parameter. Comparatively, S. occidentalis and M. pudica showed the greatest sensitivity to the allelopathic effects. For $\mathbf{S}$. obtusifolia no allelopathic effects promoted by $\mathrm{p}$-coumaric acid on seed germination or on root elongation could be detected under the concentration of 1.0 and $8.0 \mathrm{mg} \mathrm{L}^{-1}$. Root elongation was more sensitive to p-coumaric acid allelophatic effects than seed germination.
\end{abstract}

Key words: allelopathy, inhibition, weed, $p$-coumaric acid.

Recebido para publicação em 3.11.2004 e na forma revisada em 21.4.2005.

2 Embrapa Amazônia Oriental, Trav. Dr. Enéas Pinheiro S/N, 66.095-100 Belém-PA. ${ }^{3}$ Pós-graduanda em Química da Universidade Federal do Pará, Rua Augusto Corrêa 01, 66075-900 Belém-Pará. ${ }^{4}$ Professor da Universidade Federal do Pará. 


\section{INTRODUÇÃO}

As áreas de pastagens cultivadas da Região Amazônica têm sido infestadas por comunidade de plantas daninhas, que se caracterizam pela agressividade e diversidade, constituindo-se no principal fator de ordem bioeconômica a limitar a produtividade da pecuária. Historicamente, o controle dessas plantas tem sido feito via uso do fogo ou por processos químicos, utilizando-se herbicidas sintéticos. O uso do fogo tem merecido, por parte da sociedade, severas críticas, mormente pela associação com o efeito estufa e por colocar em risco o patrimônio genético das florestas da região. O uso de herbicidas sintéticos também tem suscitado insatisfações de ordem social, especialmente por estes comprometerem a qualidade dos recursos naturais, porem em perigo a vida silvestre e contaminarem os alimentos da dieta humana. Esses fatores têm indicado que novos paradigmas de controle de plantas daninhas precisam ser estabelecidos, que sejam ao mesmo tempo eficientes no controle dessas plantas, resguardem os interesses da sociedade e não contaminem os recursos naturais.

Nesse contexto, a investigação de plantas com atividade alelopática pode representar excelente oportunidade para equacionar esse problema, não só pela possibilidade de fornecer novas moléculas com potencial para compor novos produtos que possam substituir os atuais herbicidas, como também pela seleção de plantas forrageiras que possam compor as pastagens e, assim, vir a exercer controle das plantas daninhas, com reflexos positivos na qualidade e longevidade das pastagens. Em razão dessa possibilidade, nos últimos anos, alguns estudos, envolvendo a análise da atividade alelopática, foram desenvolvidos com diferentes espécies de gramineas forrageiras (Young \& Bartolomew, 1981; Smith \& Martin, 1994; Wardle et al., 1992).

As informações disponiveis mostram que gramineas forrageiras do gênero Brachiaria possuem atividade potencial alelopática, inibitória da germinação de sementes e do desenvolvimento de plantas de diferentes espécies (Almeida, 1993; Carvalho, 1993; Souza Filho et al., 1997a). Estudos desenvolvidos com essa gramínea mostraram atividade alelopática tanto nas sementes como na parte aérea e nas raízes, sendo a parte aérea a principal fonte de substâncias químicas com atividade potencialmente alelopática (Souza Filho et al., 1997b).

Para o gênero Brachiaria, as informações referentes ao isolamento e à identificação de substâncias químicas responsáveis pela atividade alelopática são muito limitadas, havendo poucas informações, como é o caso do trabalho desenvolvido com a espécie Brachiaria mutica, da qual foram isoladas e identificadas as seguintes substâncias químicas com atividade alelopática: ácido ferúlico, ácido 2,4-diidroxibenzóico, ácido vanílico, ácido $p$-hidroxibenzóico e ácido $p$-hidroxifenilacético (Chou, 1989).

Este trabalho teve por objetivos isolar, identificar e caracterizar a atividade alelopática de substâncias químicas produzidas pela gramínea forrageira Brachiaria humidicola sobre a germinação de sementes e o desenvolvimento da radícula de diferentes espécies de plantas daninhas.

\section{MATERIAL E MÉTODOS}

\section{Coleta do material botânico}

O capim-quicuio-da-amazônia (Brachiaria humidicola) foi cultivado no Campo Experimental da Embrapa Amazônia Oriental, localizado na cidade de Belém, Pará, em parcelas de 3,0 × 2,0 m, sem qualquer correção da fertilidade ou do $\mathrm{pH}$ do solo. Após três meses de cultivo, as plantas foram cortadas rente ao solo, secas em estufa de circulação de ar forçado a $40{ }^{\circ} \mathrm{C}$, por 72 horas, e trituradas em moinho do tipo faca, obtendo-se 9,0 kg de pó, acondicionado em saco plástico. Por ocasião da colheita do material vegetativo, as plantas não estavam produzindo flores ou sementes, sendo o material colhido constituído apenas de folhas e colmos.

\section{Procedimentos de isolamento e identifica- ção das substâncias químicas}

O material moído (pó) foi submetido à extração exaustiva e sucessiva, a frio, com solventes com polaridade crescente, partindose do hexano, passando pelo acetato de etila, 
metanol e terminando com a mistura de metanol e água (7:3). Cada uma dessas soluções foi filtrada a vácuo e destilada sob pressão reduzida, utilizando-se rotavapor Buchi, modelo EL 131, fornecendo os respectivos extratos brutos: hexânico (EBHX), acetato de etila (EBACEt), metanólico (EBMT) e hidrometanólico (EBHM), sendo os rendimentos obtidos apresentados no fluxograma a seguir. Todos os extratos e frações e grupos foram submetidos a avaliação quanto à capacidade de inibir a germinação das sementes da espécie daninha Mimosa pudica (malícia).
Em razão dos resultados obtidos no bioensaio de avaliação da atividade alelopática, o extrato bruto hidrometanólico (EBHM) foi destilado a vácuo (rotavapor de Buchi) até eliminação total do metanol, e a solução resultante foi submetida à partição líquido-líquido com n-hexano, diclorometano e acetato de etila, cujos rendimentos são apresentados no fluxograma.

Por apresentarem comportamentos cromatográficos similares, as frações em acetato de etila e diclorometano foram reunidas em

FLUXOGRAMA

Procedimento para isolamento e purificação do ácido $p$-cumárico na parte aérea da gramínea forrageira $B$. humidicola.

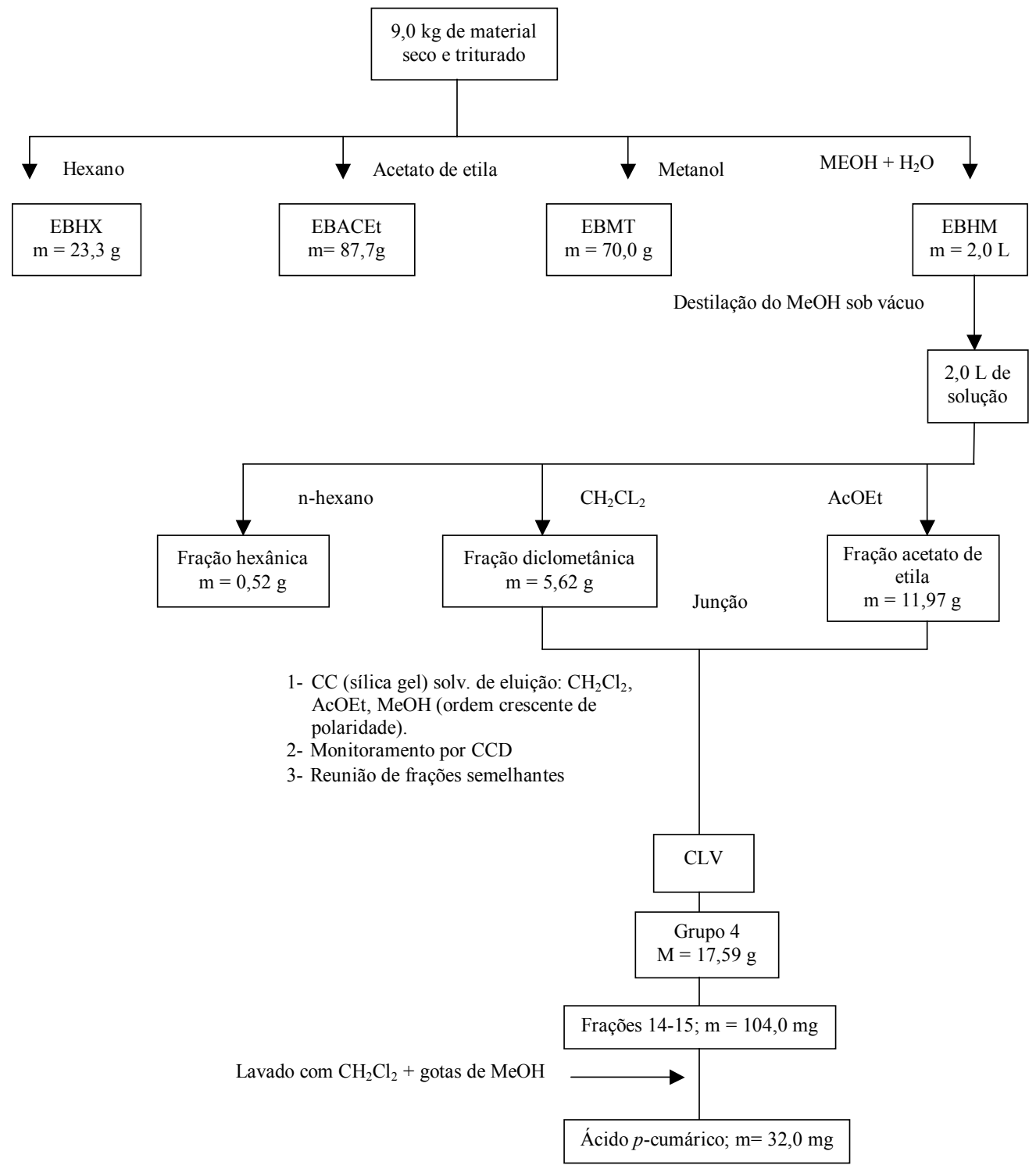

Planta Daninha, Viçosa-MG, v. 23, n. 1, p. 25-32, 2005 
uma única $(17,59 \mathrm{~g})$ e submetidas a cromatografia líquida a vácuo (CLV), em coluna de gel de sílica, utilizando-se, como eluentes, diclorometano, acetato de etila e metanol, em misturas binárias, em ordem crescente de polaridade. As frações coletadas foram reunidas, após destilação e análise por cromatografia em camada delgada, obtendo-se seis grupos de frações. Foram realizadas sucessivas cromatografias em coluna e em placa preparativa, até a purificação das substâncias químicas com atividade alelopática (Fluxograma).

A identificação estrutural foi realizada por Ressonância Magnética Nuclear $\left(\mathrm{RMN}{ }^{1} \mathrm{H}\right.$, RMN ${ }^{13} \mathrm{C}$ e de $\left.\mathrm{RMN}{ }^{13} \mathrm{C}-\mathrm{DEPT}\right)$, espectro de COSY e de HETCOR.

\section{Análise da atividade alelopática das substâncias quimicas}

A atividade alelopática dos extratos brutos, frações, grupos e substâncias isoladas foi aquilatada sobre a germinação das sementes e o desenvolvimento da radícula das plantas. Os bioensaios de germinação foram desenvolvidos em câmaras, em condições controladas de $25{ }^{\circ} \mathrm{C}$ de temperatura constante e fotoperíodo de 12 horas. A germinação foi monitorada em períodos de 10 dias, com contagens diárias e eliminação das sementes germinadas. Consideraram-se sementes germinadas aquelas que apresentavam extensão radicular igual ou superior a 2,00 mm (Juntila, 1976; Duram $\&$ Tortosa, 1985). Cada placa de Petri de $9,0 \mathrm{~cm}$ de diâmetro recebeu 20 sementes.

Os bioensaios de desenvolvimento da radícula foram desenvolvidos em câmaras, em condições controladas de $25{ }^{\circ} \mathrm{C}$ de temperatura constante e fotoperíodo de 24 horas. Cada placa de Petri de 9,0 cm de diâmetro recebeu quatro sementes pré-germinadas, com aproximadamente três dias de germinação. Ao final do período de dez dias de crescimento, mediu-se o comprimento da radícula.

\section{Outros procedimentos experimentais}

As avaliações dos extratos brutos foram feitas na concentração de $1 \%$. Para as frações e grupos foi empregada a concentração de $0,5 \%$ e, para as avaliações dos efeitos das substâncias químicas isoladas, as concentrações de 1,0; 2,0; 3,0; 4,0; e 8,0 $\mathrm{mg} \mathrm{L}^{-1}$, tendo como eluente o metanol. Cada placa de Petri de 9,0 cm de diâmetro recebeu $3,0 \mathrm{~mL}$ de extratos brutos, bem como das frações, subfrações e substâncias químicas. O material avaliado foi adicionado apenas uma vez, no início de cada bioensaio, sendo adicionada, a partir de então, apenas água destilada, quando necessário. Após a adição de extratos brutos, frações, grupos subfrações e substâncias, deixou-se evaporar o solvente e adicionar-se 3,0 mL de água destilada, mantendo, dessa forma, a concentração original.

Como planta receptora foram utilizadas as espécies daninhas de área de pastagem cultivada malícia (Mimosa pudica L.), matapasto (Senna obtusifolia) e fedegoso (Senna Occidentalis). As sementes dessas plantas foram coletadas em áreas de pastagens cultivadas do município de Castanhal-PA. Elas passaram por um processo de limpeza e foram tratadas com vistas à superação da dormência, utilizando-se o ácido sulfúrico concentrado (Souza Filho et al., 1998).

\section{Análise estatística}

O delineamento experimental foi o inteiramente casualizado, com três repetições. Os dados foram submetidos à análise de variância pelo teste $\mathrm{F}$ e as médias comparadas pelo teste de Tukey (5\%). Os dados foram analisados, utilizando-se o programa estatístico SAS (SAS, 1989).

\section{RESULTADOS E DISCUSSÃO}

\section{Isolamento e identificação das substâncias químicas}

No Fluxograma é mostrado o procedimento de isolamento e purificação que possibilitou a identificação do ácido $p$-cumárico, na forma de um sólido amorfo. Cada fase do processo foi acompanhada de avaliações, para se identificar em que porção estava a atividade alelopática. A avaliação inicial permitiu identificar que a substância se encontrava no extrato bruto hidrometanólico (EBHM) e que ela possuía polaridade intermediária entre o metanol e a água (Figura 1). A análise das três frações obtidas desse extrato bruto indicou a fase diclorometano como a que concentrava essa substância (Figura 2). 


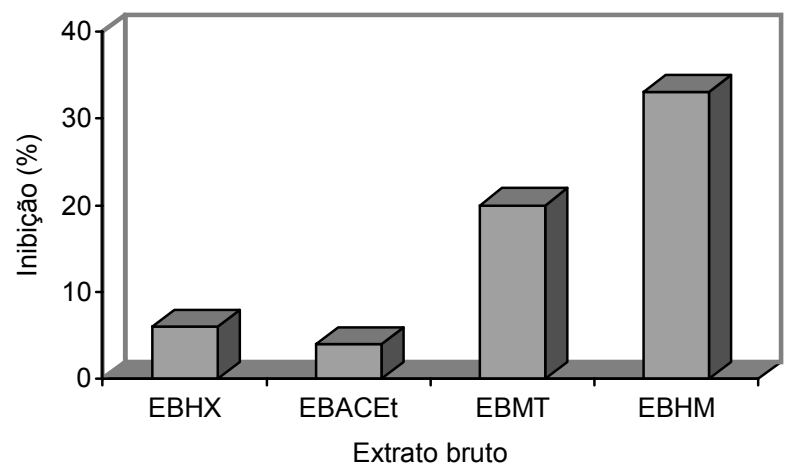

Figura 1 - Efeitos dos extratos brutos sobre a germinação de sementes da espécie daninha malícia. Dados expressos em percentual de inibição em relação ao tratamento testemunha (água destilada).

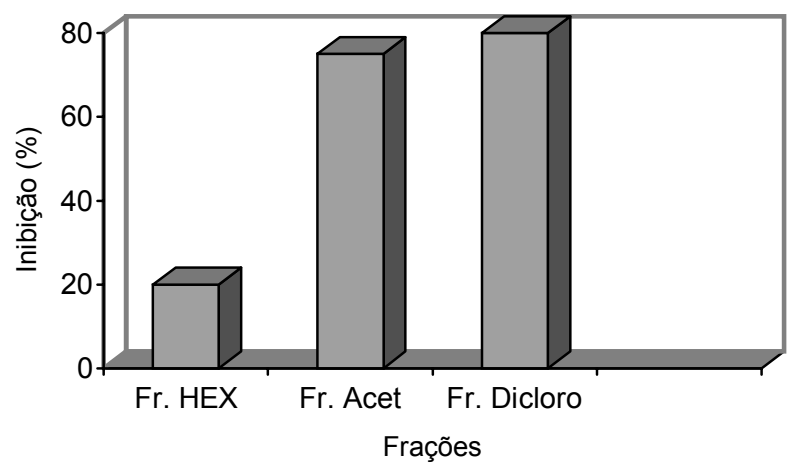

Figura 2 - Efeitos das frações obtidas do extrato bruto hidrometanólico sobre a germinação de sementes da espécie daninha malícia. Dados expressos em percentual de inibição em relação ao tratamento testemunha (água destilada).

Partindo-se dessa fração, foram obtidos seis grupos de diferentes polaridades, cuja avaliação da atividade alelopática apontou o grupo 4 como o responsável pelas atividades alelopáticas (Figura 3). O refracionamento desse grupo permitiu a obtenção de várias frações de polaridades diferentes, de cuja fração 14-15 foi isolado o ácido $p$-cumárico.

O espectro de $\mathrm{RMN}^{1} \mathrm{H}$ mostrou a presença de dois dupletos, um em $\delta 7,4\left(\mathrm{~J}_{\text {orto }}=8,7 \mathrm{~Hz} ; 2 \mathrm{H}\right)$ e outro em $\delta 6,8\left(\mathrm{~J}_{\text {orto }}=8,7 \mathrm{~Hz} ; 2 \mathrm{H}\right)$, referentes aos hidrogênios do grupo fenila. Os dupletos $\operatorname{em~} \delta 7,6\left(\mathrm{~J}_{\text {trans }}=15,9 \mathrm{~Hz} ; 1 \mathrm{H}\right)$ e $\delta 6,2\left(\mathrm{~J}_{\text {trans }}=\right.$ $15,9 \mathrm{~Hz} ; 1 \mathrm{H})$ são devidos aos hidrogênios olefínicos, $\mathrm{H}-1$ ' e $\mathrm{H}-2$ ', respectivamente (Tabela 1). Com base nesses resultados e nas análises de RMN ${ }^{13} \mathrm{C}$ e espectro de massas, comparados com dados da literatura
(Gerothanassis et al., 1998; Pouchert, 1983), a substância foi identificada como o ácido p-cumárico, um fenilpropanóide precursor da biossintese dos flavonóides (Figura 4).

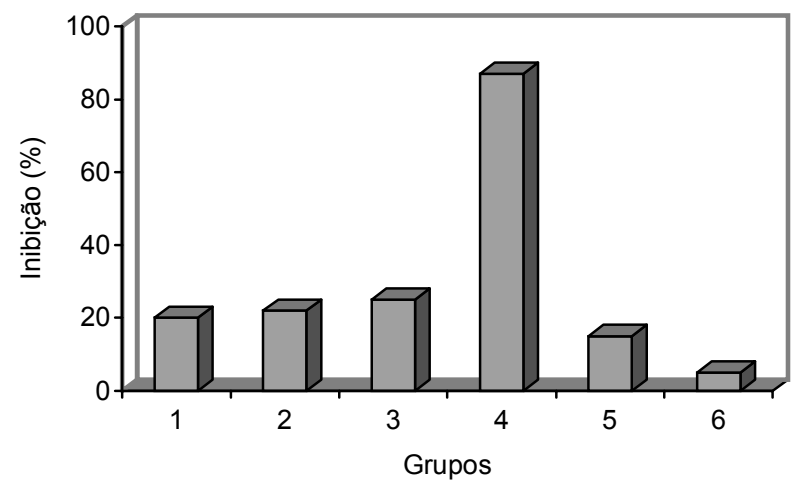

Figura 3 - Efeitos dos grupos de frações obtidos por cromatografia em coluna a vácuo (CLV) sobre a germinação de sementes da espécie daninha malícia. Dados expressos em percentual de inibição em relação ao tratamento testemunha (água destilada).

Tabela 1 - Dados de $\mathrm{RMN}{ }^{1} \mathrm{H}$ (ppm, $\left.\mathrm{CD}_{3} \mathrm{OD}, 300 \mathrm{MHz}\right) \mathrm{e}$ ${ }^{13} \mathrm{C}$ (ppm, $\mathrm{CD}_{3} \mathrm{OD}, 75 \mathrm{MHz}$ ) do ácido p-cumárico identificado na parte aérea da gramínea forrageira Brachiaria humidicola

\begin{tabular}{|c|c|c|}
\hline Posição & ${ }^{1} \mathrm{H}$ & ${ }^{13} \mathrm{C}$ \\
\hline 1 & & 127,3 \\
\hline 2 e 6 & $7,4(d ; \mathrm{J}=8,7 \mathrm{~Hz} ; 2 \mathrm{H})$ & 131,0 \\
\hline 3 e 5 & $6,8(d ; \mathrm{J}=8,7 \mathrm{~Hz} ; 2 \mathrm{H})$ & 116,8 \\
\hline 4 & & 161,0 \\
\hline $1^{\prime}$ & $7,6(d ; \mathrm{J}=15,9 \mathrm{~Hz} ; 1 \mathrm{H})$ & 146,6 \\
\hline $2^{\prime}$ & $6,3(d ; \mathrm{J}=15,9 \mathrm{~Hz} ; 1 \mathrm{H})$ & 115,7 \\
\hline $3^{\prime}$ & & 171,2 \\
\hline
\end{tabular}

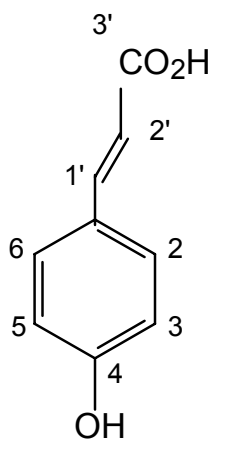

Figura 4 - Estrutura do ácido $p$-cumárico.

Planta Daninha, Viçosa-MG, v. 23, n. 1, p. 25-32, 2005 
O ácido $p$-cumárico, à semelhança do presente trabalho, foi isolado em diferentes espécies de plantas, como arroz, cana-de-açúcar, leucena, pinus preto e gliricídia, e em cereais (Baghestani et al., 1999; Rice, 1992; Chou, 1992; Kil, 1992; Ramamoorthy \& Paliwat, 1993). Especificamente com relação ao gênero Brachiaria, esse ácido foi isolado na graminea forrageira Brachiaria mutica por Chou (1992).

\section{Avaliação da atividade alelopática do ácido p-cumárico}

Os efeitos alelopáticos inibitórios promovidos pelo ácido $p$-cumárico variaram em função do parâmetro da planta analisado, da concentração do ácido e da espécie de planta daninha utilizada como teste. Independentemente da espécie, os efeitos inibitórios variaram positivamente com o aumento da concentração, sendo as inibições mais intensas verificadas na concentração de $8,0 \mathrm{mg} \mathrm{L}^{-1}$ (Tabelas 2 e 3).

A inibição da germinação das sementes (Tabela 2) foi baixa, notadamente nas concentrações de 1,0 a 3,0 $\mathrm{mg} \mathrm{L}^{-1}$, não ultrapassando $7,0 \%$. Mesmo na concentração mais alta $\left(8,0 \mathrm{mg} \mathrm{L}^{-1}\right)$ a inibição máxima não ultrapassou os $32,0 \%$. Esses efeitos contrastam com os disponiveis na literatura, que mostram o ácido p-cumárico como um potente inibidor da germinação (Baskin et al., 1967; Alves \& Souza Filho, 2002). Aparentemente, essa diferença está associada à especificidade entre o ácido e as espécies receptoras.

Considerando os efeitos inibitórios promovidos sobre a germinação das sementes (Tabela 2) de cada uma das espécies receptoras, fedegoso foi a espécie que se mostrou mais suscetivel aos efeitos do ácido $p$-cumárico, registrando inibições da ordem de 18,0\% e 32,0\% nas concentrações de 4,0 e 8,0 $\mathrm{mg} \mathrm{L}^{-1}$, respectivamente. A espécie mata-pasto não teve a germinação das sementes inibida pelo ácido $p$-cumárico em qualquer das concentrações testadas.

Os dados apresentados na Tabela 3 mostram que o desenvolvimento da radícula foi intensamente inibido pelo ácido $p$-cumárico, em todas as concentrações. À semelhança dos efeitos observados sobre a germinação das sementes, os efeitos inibitórios promovidos pelo ácido $p$-cumário também estiveram positivamente relacionados à concentração do ácido, com as menores e maiores inibições observadas nas concentrações de 1,0 e $8,0 \mathrm{mg} \mathrm{L}^{-1}$, respectivamente. Para concentração tão baixa quanto $1,0 \mathrm{mg} \mathrm{L}^{-1}$, inibições da ordem de $25,0 \%$ e $55,0 \%$ sobre o desenvolvimento da radícula do fedegoso e da malícia foram observadas, enquanto para concentrações de $8,0 \mathrm{mg} \mathrm{L}^{-1}$ inibições de $42,0 \%$ foram verificadas para o desenvolvimento da radícula do fedegoso e de 80,0\% para a malícia. Repetindo os resultados encontrados sobre a germinação das sementes, a espécie matapasto não teve o desenvolvimento da radícula afetado pelo ácido $p$-cumárico nas concentrações de 1,0 a 8,0 $\mathrm{mg} \mathrm{L}^{-1}$ (Tabela 3).

Tabela 2 - Efeitos do ácido $p$-cumárico sobre a germinação de sementes de diferentes espécies daninhas de área de pastagens cultivadas. Dados expressos em percentual de inibição em relação ao tratamento testemunha (água destilada)

\begin{tabular}{|c|c|c|c|}
\hline \multirow{2}{*}{$\begin{array}{c}\text { Ácido } p \text {-cumárico } \\
\left(\mathrm{mg} \mathrm{L}^{-1}\right)\end{array}$} & \multicolumn{3}{|c|}{ Espécie de planta daninha } \\
\cline { 2 - 4 } & Fedegoso & Malícia & Mata-pasto \\
\hline 1,0 & $3,0 \mathrm{Da}$ & $2,0 \mathrm{DCa}$ & $2,0 \mathrm{Aa}$ \\
\hline 2,0 & $5,0 \mathrm{CDa}$ & $3,0 \mathrm{Cdab}$ & $2,0 \mathrm{Ab}$ \\
\hline 3,0 & $7,0 \mathrm{Ca}$ & $5,0 \mathrm{Cb}$ & $3,0 \mathrm{Ab}$ \\
\hline 4,0 & $18,0 \mathrm{Ba}$ & $11,0 \mathrm{Bb}$ & $4,0 \mathrm{Ac}$ \\
\hline 8,0 & $32,0 \mathrm{Aa}$ & $28,0 \mathrm{Ab}$ & $4,0 \mathrm{Ac}$ \\
\hline
\end{tabular}

Médias seguidas de letras iguais, maiúsculas na coluna e minúsculas na linha, não diferem pelo teste de Tukey $(\mathrm{p}>0,05)$.

Tabela 3 - Efeitos do ácido $p$-cumárico sobre o desenvolvimento da radícula de diferentes espécies daninhas de pastagens cultivadas. Dados expressos em percentual de inibição em relação ao tratamento testemunha (água destilada)

\begin{tabular}{|c|c|c|c|}
\hline \multirow{2}{*}{$\begin{array}{c}\text { Ácido } p \text {-cumárico } \\
\left(\mathrm{mg} \mathrm{L}^{-1}\right)\end{array}$} & \multicolumn{3}{|c|}{ Espécie de planta daninha } \\
\cline { 2 - 4 } & Fedegoso & Malícia & Mata-pasto \\
\hline 1,0 & $25,0 \mathrm{Db}$ & $55,0 \mathrm{Ea}$ & $5,0 \mathrm{Ac}$ \\
\hline 2,0 & $27,0 \mathrm{CDb}$ & $64,0 \mathrm{Da}$ & $5,0 \mathrm{Ac}$ \\
\hline 3,0 & $30,0 \mathrm{Cb}$ & $70,0 \mathrm{Ca}$ & $6,0 \mathrm{Ac}$ \\
\hline 4,0 & $35,0 \mathrm{Bb}$ & $77,0 \mathrm{Ba}$ & $7,0 \mathrm{Ac}$ \\
\hline 8,0 & $42,0 \mathrm{Ab}$ & $80,0 \mathrm{Aa}$ & $7,0 \mathrm{Ac}$ \\
\hline
\end{tabular}

Médias seguidas de letras iguais, maiúsculas na coluna e minúsculas na linha, não diferem pelo teste de Tukey $(\mathrm{p}>0,05)$. 
Comparativamente, os efeitos alelopáticos promovidos pelo ácido $p$-cumário foram mais intensos sobre o desenvolvimento da radícula do que sobre a germinação das sementes. Para promover inibições acima de 10,0\% sobre a germinação das sementes das espécies fedegoso e malícia, foram necessárias concentrações iguais ou superiores a $4,0 \mathrm{mg} \mathrm{L}^{-1}$ de ácido p-cumárico (Tabela 2). Já em relação aos efeitos sobre o desenvolvimento da radícula, mesmo a $1,0 \mathrm{mg} \mathrm{L}^{-1}$, inibições da ordem de $25,0 \%$, para fedegoso, e 55,0\%, para malícia, foram observadas (Tabela 3). Para fedegoso, concentração igual a $3,0 \mathrm{mg} \mathrm{L}^{-1}$ efetivou inibição sobre o desenvolvimento da radícula equivalente à promovida sobre a germinação das sementes em concentração de $8,0 \mathrm{mg} \mathrm{L}^{-1}$. Similarmente, para malícia, a concentração de $1,0 \mathrm{mg} \mathrm{L}^{-1}$ resultou em redução, no desenvolvimento da radícula, equivalente ao dobro da promovida na germinação das sementes, na concentração de $8,0 \mathrm{mg} \mathrm{L}^{-1}$ Esses resultados indicam o desenvolvimento da radícula como um fator mais sensivel aos efeitos alelopáticos do ácido $p$-cumárico do que a germinação das sementes.

As informações disponiveis indicam que a atividade biológica de um aleloquímico depende tanto da concentração do aleloquímico como do limite da resposta da espécie afetada (Reigosa et al., 1999; Abrahim et al., 2000; Kato-Naguchi et al., 1994). No presente trabalho, esses dois pontos foram bem marcantes quando se observa a relação positiva entre a concentração e a inibição da germinação das sementes (Tabela 2) e do desenvolvimento da radícula (Tabela 3 ).

A variação no limite de resposta das espécies receptoras aos efeitos das diferentes concentrações do ácido $p$-cumárico também foi observada neste trabalho (Tabelas 2 e 3). Souza Filho et al. (2003) atribuem esses resultados ao tamanho das sementes das espécies daninhas. Neste trabalho, foi observado que espécies com sementes maiores (mata-pasto) tiveram a germinação de suas sementes e o desenvolvimento da radícula afetados em menor magnitude do que malícia, que possuía sementes menores em comparação com mata-pasto e fedegoso.
Rice (1984) menciona que, quando em baixas concentrações, as substâncias alelopáticas podem não ser inibitórias para determinadas espécies ou até mesmo apresentar efeitos estimulatórios. Os resultados desses trabalhos não mostraram efeitos estimulatórios em baixas concentrações, talvez porque a concentração mais baixa $\left(1,0 \mathrm{mg} \mathrm{L}^{-1}\right)$ possa estar acima daquela requerida, em se tratando das espécies receptoras utilizadas, para reais efeitos estimulatórios. Ausência de resposta, entretanto, foi observada especificamente para a germinação das sementes nas concentrações de 1,0 e 2,0 $\mathrm{mg} \mathrm{L}^{-1}$ (Tabela 2).

\section{LITERATURA CITADA}

ABRAHIM, D. et al. Effects of four monoterpenes on germination, primary root growth, and mitochondrial respiration of maize. J. Chem. Ecol., v. 26, n. 2, p. 611-624, 2000.

ALMEIDA, A. R. P. Efeitos alelopáticos de espécies de Brachiaria Griseb sobre algumas leguminosas tropicais. 1993. 73 f. Dissertação (Mestrado em Zootecnia) Universidade de São Paulo, Piracicaba, 1993.

ALVES, S. M.; SOUZA FILHO, A. P. S. Natureza química dos agentes alelopáticos. In: SOUZA FILHO, A. P. S.; ALVES, S. M. (Eds.) Alelopatia: princípios básicos e aspectos gerais. Belém: Embrapa, 2002. p. 25-47.

BAGHESTANI, A. et al. Determination of allelochemicals in spring cereal cultivars of different competitiveness. Weed Sci., v. 47, p. 498-504, 1999.

BASKIN, J. M.et al. Psoralea, an inhibitor in the seeds of Psoralea subcaulis (leguminosae). Phytochemistry, v. 6, p. 1209, 1967.

CARVALHO, S. J. C. Caracterização dos efeitos alelopáticos de Brachiaria brizantha cv. Marandu no estabelecimento das plantas de Stylosanthes guianensis var. vulgaris e cv. Bandeirante. 1993. 72 f. Dissertação (Mestrado em Zootecnia) - Universidade Federal de Viçosa, Viçosa, 1993.

CHOU, C. H. Allelopathy in relation to agriculture productivity in Taiwan: problem and prospects. In: RIZVI, S. J. H.; RIZVI, V. (Eds.). Allelopathy. London: Chapman \& Hall, 1992. p. 179-203.

CHOU, C. H. Allelopathic research of subtropical vegetation in Taiwan. IV. Comparative phytotoxic nature of leachate from four subtropical grasses. J. Chem. Ecol., v. 15, n. 7, p. 2149-2159, 1989.

Planta Daninha, Viçosa-MG, v. 23, n. 1, p. 25-32, 2005 
DURAM, J. M.; TORTOSA, M. E. The effect of mechanical and chemical scarification on germination of charlock (Sinapsis arvensis L.) seeds. Seed Sci. Technol., v. 13, n. 1, p. 155-163, 1985.

GEROTHANASSIS, I. P. et al. Methodology for identification of phenolic acids in complex phenolic mixtures by high-resolution two-dimensional nuclear magnetic resonance of two oregano species. J. Agric. Food Chem., v. 46, p. 4185-4192, 1998.

JUNTILA, O. Seed and embryo germination in $S$. vulgaris and $S$ reflexa as affected by temperature during seed development. Physiol. Plant., v. 29, p. 264-268, 1976.

KATO-NAGUCHI, H. et al. Allelopathy of oats. I. Assessment of allelopathic potential of extract of oat shoots an identification of an allelochemical. J. Chem. Ecol., v. 20, n. 2, p. 309-314, 1994.

KIL, B. S. Effect of pine allelochemicals on selected species in Korea. In: RIZVI, S.J.H.; RIZVI, V. Allelopathy. London: Chapman \& Hall, 1992. p. 205-241.

POUCHERT, C. S. The aldrich library of NMR spectra. 2.ed. USA: Aldrich Chemical Company, 1983. p. 179.

RAMAMOORTHY, M.; PALIWAT, K. Allelopathic compounds in leaves of Gliricidia sepium (Jacq.) Kunth ex Walp. And its effect. J. Chem. Ecol., v. 19, n. 8, p. 16911701, 1993.

REIGOSA, M. J.; SÁNCHEZ-MOREIRA, A.;

GONZÁLES, L. Ecophysiological approach in allelopathy. Crit. Rev. Plant Sci., v. 18, n. 5, p. 577-608, 1999.

RICE, E. L. Allelopathic effects on nitrogen cycling. In: RIZVI, S.J.H.; RIZVI, V. (Eds.). Allelopathy. London: Chapman \& Hall, 1992. p. 31-58.
RICE, E. L. Allelopathy. New York: Academic Press, 1984. $422 \mathrm{p}$.

SMITH, A. E.; MARTIN, D. L. Allelopathic characteristics of three cool-season grass in the forage ecosystems. Agron. J., v. 8, n. 2, p. 243-246, 1994.

SOUZA FILHO, A. P. S.; ALVES, S. M.; FIGUEIREDO, F. J. C. Efeitos alelopáticos do calopogônio em função da sua idade e da densidade de sementes da planta receptora.

Planta Daninha, v. 21, n. 2, p. 211-218, 2003.

SOUZA FILHO, A. P. S.; RODRIGUES, L. R. A.; RODRIGUES, T. J. D. Potencial alelopático de forrageiras tropicais: efeitos sobre invasoras de pastagens. Planta Daninha, v. 15, n. 1, p. 53-60, 1997a.

SOUZA FILHO, A. P. S.; RODRIGUES, L. R. A.; RODRIGUES, T. J. D. Inibição da germinação e alongamento da radícula de invasoras de pastagens pelos extratos aquosos de gramíneas forrageiras tropicais.

Pasturas Trop., v. 19, n. 1, p. 45-50, 1997 b.

SOUZA FILHO, A. P. S.; DUTRA, S.; SILVA, M. A. M. M. Métodos de superação da dormência de sementes de plantas daninhas de pastagens cultivadas da Amazônia. Planta Daninha, v. 16, n. 1, p. 3-11, 1998.

STATISTICAL ANALYSIS SYSTEM - SAS. User's guide. Version 6.4. Cary: 1989. 846 p.

WARDLE, D. A.; NICHOLSON, K. S.; RAHMED, A. Influence of pasture grass and legumes swards on seedling emergence and growth of Carduus nutans L. and Cirsium vulgare L. Weed Res., v. 32, n. 2, p. 119-128, 1992.

YOUNG, C. C.; BARTOLOMEW, D. P. Allelopathy in grass-legumes association. I-Effects of Hemarthria altissima (pPoir) Stapf. And Hubb. Root residues on the growth of Desmodium intortum (Mill) Urb. And Hermathria altissima in a tropical soil. Crop Sci., v. 21, p. 770-774, 1981. 